\title{
La serie de Televisión Española “Águila Roja” desde una perspectiva audiométrica (2009-2012)
}

\author{
Recibido: 01 de octubre de 2013 \\ Aceptado: 18 de julio de 2014 \\ Publicado: 28 de noviembre de 2014
}

\author{
Mónica Barrientos Bueno \\ mbarrientos@us.es
}

Universidad de Sevilla (España)

Resumen: “Águila Roja”, la serie de Globomedia emitida por la cadena de televisión pública nacional española TVE, se ha convertido en los últimos años en un interesante fenómeno de audiencia en España; por ello se realiza una investigación distributiva de audiencias con la que poder indagar en su evolución desde su estreno en febrero de 2009 hasta enero de 2012, estableciendo comparativas con los datos de audiencias medias, máximas y share por temporadas y capítulos. Igualmente se han contextualizado estos datos en el ámbito de las audiencias para aportar una visión global de los mismos.

Palabras clave: Audiencia, serie de televisión, “Águila Roja”, Globomedia, TVE.

Abstract: "Águila Roja”, Globomedia's TV series broadcasted by the Spanish public national wide television TVE (Televisión Española), has been turned into an interesting audience phenomenon in the last years in Spain; that's the reason why it has been made a distributive audience research, a way to make inquiries about this TV series evolution from February 2009 to January 2012 with audience's average, golden minute and share data comparisons by seasons and episodes. At the same time this information has been set in the environment in which the episodes were broadcasted to get a global wide vision.

Key words: Audience, TV Series, “Águila Roja”, Globomedia, TVE.

\section{Introducción}

Producida por la productora española Globomedia, "Águila Roja”, serie de La 1 de Televisión Española (TVE), entrega tras entrega congrega ante el televisor un abultado número de espectadores que en su cuarta temporada de emisión ha superado los seis 
millones de audiencia media en nueve de sus doce episodios. Conviene tener en cuenta, para poner en perspectiva los datos de "Águila Roja", el actual contexto de audiencias fragmentadas donde cada vez es más difícil congregar tantos televidentes ante la pantalla, de hecho apenas una docena de espacios superan habitualmente el $20 \%$ de share cada mes en España.

“Águila Roja” es una especie de rara avis en el entorno televisivo español actual al generar un fenómeno de audiencias, a nivel de cifras, poco común en los tiempos que corren. Aunque la "investigación distributiva de audiencias" ${ }^{2}$ tiene como propósito esencial establecer el mercado publicitario, los datos que reflejan los audímetros dejan un margen para otro tipo de miradas y lecturas; precisamente aquí es donde encuentra su lugar y se asienta esta investigación: conocer la progresión contextualizada de audiencia de esta apuesta de Globomedia que emite TVE, en un mercado en el que además, desde 2010, se hace sin cortes publicitarios desde la supresión de ingresos por publicidad comercial de la televisión pública estatal.

“Águila Roja” se ha convertido en una serie de gran influencia debido a que su favor entre el público ha rescatado un género olvidado desde hace décadas en la producción televisiva de ficción seriada española, abriendo el camino a otras que abordan la temática del pasado histórico desde perspectivas tan dispares como la aventura, la épica o el estricto rigor y ceñimiento a los hechos reales.

\section{Objetivos}

Los objetivos planteados son, desde un punto de vista general, analizar el fenómeno de audiencia de la producción de Globomedia “Águila Roja”, entre 2009 y 2012, en su primer pase en $L a 1$ de $\mathrm{TVE}^{3}$ (del capítulo uno de la primera temporada al doce de la cuarta, cincuenta y uno en total), y específicamente estudiar la variación de los flujos de espectadores que la siguen a lo largo de todas las temporadas emitidas hasta este momento, inscribiéndolos en su contexto, a través de las comparativas de audiencia media, share y audiencia máxima, apuntando los techos y suelos tanto por temporada como en el global de la serie.

Un segundo objetivo específico ha sido aportar una perspectiva más amplia al estudio audiométrico, que trascienda el entorno inmediato de la serie en sí, a través del análisis de

\footnotetext{
1. Factores esenciales de fragmentación, en el ámbito español, son: el cambio poblacional por envejecimiento debido al incremento de la esperanza de vida y del número de inmigrantes residentes, la metamorfosis del equipamiento tecnológico audiovisual e informático del hogar, la transformación y ampliación del marco de los sistemas de distribución del producto audiovisual (Televisión Digital Terrestre, cable, satélite, Internet), la división del consumo y de la preferencia televisiva producida por la multiplicación de la oferta de la pequeña pantalla y, en último lugar, la modificación y evolución de los propios contenidos audiovisuales (Vaca, 2009: 39-91).
}

2. Expresión empleada por Callejo (2001: 120) para denominar a las investigaciones de medición de audiencias, es decir, las realizadas con técnicas cuantitativas.

3. Los capítulos han tenido reemisiones en Clan TV y TVE-HD. 
otros indicadores como la situación de "Águila Roja" en lo que a audiencia se refiere, a lo largo del periodo de estudio, en el ámbito de la ficción nacional y de las emisiones más vistas cada año, donde se incluyen todos los géneros y formatos que tienen cabida en la pequeña pantalla (retransmisiones deportivas, informativos, concursos, entre otros).

\section{Metodología}

Para abordar esta investigación, a nivel metodológico, se ha realizado una recopilación de los datos de audiencia del periodo estudiado (entre febrero de 2009 y enero de 2012), tanto de "Águila Roja" como de otros programas y series con los que ha compartido día de emisión y franja horaria a partir de dos fuentes principales: webs que ofrecen diariamente esta información ${ }^{4}$ y la propia página oficial de la serie (http://www.rtve.es/televison/aguilaroja), además de informes mensuales y anuales de audiencia cuya fuente son audimetrías ${ }^{5}$.

El volumen de datos manejado, de naturaleza dispersa, se ha ordenado y procesado por temporadas (cuatro en total entre febrero de 2009 y enero de 2012), confeccionándose al efecto tablas y gráficos que han facilitado el estudio de las variaciones de audiencia y, en consecuencia, la extracción de conclusiones al respecto. Los cifras en sí, descontextualizadas, no son el objeto prioritario de este estudio, por ello se ha recurrido a la investigación de otros aspectos que afectan al incremento o aumento del número de espectadores de los episodios incluidos en este estudio, relacionando la emisión con lo ofrecido en ese momento por otras cadenas de televisión, los meses y días en los que TVE, en La 1, ha programado cada una de las temporadas, entre otras variables que se han considerado.

Paralelamente se ha requerido un amplio marco teórico que ofreciera las pertinentes pautas metodológicas con las cuales abordar científicamente el estudio audiométrico de la serie "Águila Roja". Este referente ha sido inestimable para acotar la investigación distributiva de audiencias y conocer los mecanismos con los que funciona.

\section{La investigación en audiencias}

El análisis e investigación en audiencias se ubica en el entorno de los estudios culturales. Como apunta Schroeder (ápud Huertas, 2002: 53) todas las investigaciones de audiencias en los medios de comunicación tienen un objetivo común: ahondar en el conocimiento de cómo los grupos sociales, sin perder el horizonte de la sociedad y la cultura, hacen uso

4. Estas páginas electrónicas son Fórmula TV (www.formulatv.com) y Vertele (www.vertele.com).

5. El audímetro se trata de la principal herramienta de investigación en televisión actualmente (cf. Planas, 2003: 97). Se ha accedido concretamente a los elaborados por Kantar Media (http://kantarmedia.es) y sus boletines mensuales de audiencia de enero-abril y septiembre-noviembre de 2010, septiembre-diciembre de 2011 y enero de 2012), así como los de Barlovento Comunicación (http://www.barloventocomunicacion.es) y Panorama audiovisual, editados por EGEDA. 
de los medios y cómo estos, en contrapartida, pueden ser agentes tanto de cambio social como de estabilidad. El interés por medir la audiencia y, en consecuencia, por saber quién consume los media en un momento determinado y en qué forma, surge con los propios medios de comunicación social, de manera que tiene una larga tradición.

Por ello, como señala Callejo (cf. 2001: 35-38), la audiencia se erige como un ente abstracto si la investigación no le diera realidad; así su análisis tiene su comienzo y fin en el conocimiento del receptor en un proceso de comunicación, es un trabajo de concreción del mismo. Si delimitamos el marco teórico al ámbito que nos compete, el televisivo, hay que considerar que el auge de los estudios de audiencias en los últimos años viene motivado por un cambio de contexto: de un mercado monopolístico e inmovilista a otro más dinámico por la multiplicación de las ofertas tanto de canales como de tecnologías de distribución (digital, satélite, cable).

En el intento por acotar qué es la audiencia nos encontramos con tantas definiciones como teóricos, las cuales nunca pierden el referente del hecho social que lo constituye, desde las más simples: "es un conjunto de receptores" (ibídem: 35), hasta otras más complejas: "conjunto segmentado a partir de sus interacciones mediáticas de sujetos sociales, activos e interactivos, que no dejan de ser lo que son mientras entablan alguna relación siempre situada con el referente mediático, sea esta directa, indirecta o diferida" (Orozco, 2011: 23), pasando por las más prácticas: "como magnitud absoluta, puede definirse como el conjunto de individuos que mantiene contacto con un medio, en nuestro caso con una cadena de televisión, a través de un programa o espacio publicitario, y durante un período de tiempo determinado" (Jauset, 2000: 228). Dada la naturaleza de nuestra investigación, vamos a adoptar como definición de referencia esta última, enunciada por Jauset, por circunscribirse de forma más ajustada y pragmática a la realidad de la audiencia televisiva.

Los estudios de audiencia conocen dos vertientes en relación al tipo de técnicas de investigación social empleadas: cuantitativa y cualitativa. La primera constituye, en televisión, el referente diario que determina el éxito o fracaso de la propuesta programática de la jornada anterior; de forma práctica supone la cotización de las diferentes ofertas puestas a disposición de los telespectadores. Este tipo de análisis consiste en la contabilización del mero contacto por parte del receptor, es decir, se materializa en sumas de individuos que se relacionan con un mensaje de un determinado medio de comunicación, en el fondo personas singulares y subjetivas en distintas circunstancias ( $c f$. Morley, 1996: 252), sin embargo incluir estos rasgos supondría la imposibilidad de producir el rating ${ }^{6}$. De forma que la técnica cuantitativa genera una audiencia atomizada, anónima, no estructurada y cuantificable, que permite el manejo de promedios y patrones generalizables.

Por su parte, los estudios realizados con técnicas cualitativas indagan en los diferentes aspectos de la recepción y los hábitos televisivos atendiendo a grupos sociales que varían en relación a la naturaleza de la investigación. De esta forma se busca el sentido de la

6. Es el número total de individuos viendo la televisión en un momento concreto (o periodo de tiempo determinado); la cifra obtenida como rating es el universo de referencia para obtener las cuotas de pantalla (cf. Jauset, 2000: 239). 
relación de los individuos con el medio, profundizando en elementos como el tiempo de consumo, si se hace en soledad o en compañía, si se le dedica atención exclusiva o mientras se realiza otra actividad, etc.; es decir, generan una audiencia en su entorno inmediato.

Tanto Callejo ( $c f .2001: 18$ ) como Jauset apuntan la idoneidad de la integración de ambas técnicas de investigación: “interesa quién, durante cuánto tiempo, cuándo y qué ve [...] Es interesante, pues, que los estudios de audiencia indiquen o den a conocer ambos aspectos, cuantitativos y cualitativos. La medición de audiencias, en sí, es un método predominantemente cuantitativo, aunque ofrece también una descripción cualitativa al conocerse la composición sociodemográfica y permitir relacionar las tipologías de los telespectadores con las de la oferta televisiva" (Jauset, 2003: 59).

En lo que respecta a la investigación distributiva de audiencias, el método de toma de datos más difundido en el entorno televisivo es el audímetro ${ }^{7}$, el cual proporciona una abundante y detallada información minuto a minuto. Entre las críticas al mismo suele apuntarse que el proceso de selección de las muestras representativas viene marcado por su arbitrariedad, a lo que se unen otros problemas como la alta proporción de abandonos del panel a pesar de la rotación anual del $25 \%$, la resistencia de algunos sectores sociales a ser observados y analizados, y el que las muestras son de individuos en residencias principales, excluyendo las secundarias o la recepción de televisión en espacios públicos, por ejemplo (Callejo, 2001: 133-134). Con el paso del tiempo se ha consolidado, por parte de las empresas encargadas de la recogida de estos datos, una selección lo más representativa de la realidad social y geodemográfica del país. Sin embargo, desde el punto de la vista de la recepción, el reducido tamaño de las muestras y el número de variables manejado para segmentar las audiencias continúan siendo muy restringidos aún cuando, estadísticamente, son suficientemente representativos.

Los estudios de audiencias, especialmente los cuantitativos, no pueden desvincularse de su utilidad mercantilista y económica; por una parte, los programadores recurren a ellos para diseñar unas parrillas lo más rentables posibles en términos económicos, además de poder adelantarse a futuras tendencias. Para el ámbito publicitario se convierten en un instrumento con el que planificar estrategias, pensando en la audiencia en términos de consumidores; estos son ofrecidos por los medios como mercancía a sus clientes: el sector de la publicidad. Junto a ello, el precio de los espacios publicitarios televisivos se determina a partir de la audiencia obtenida en cada segmento concreto de la parrilla, pujando la publicidad por aquellos programas que en determinadas granjas horarias mayor concentración de espectadores tienen. Precisamente este factor es el que ha impulsado, en los últimos años, la relevancia de los estudios cuantitativos: los medios han de justificar ante el anunciante el resultado de la inversión publicitaria realizada, en consecuencia estamos hablando de un imperativo industrial y la audiencia es la "moneda de intercambio para medios y anunciantes" (González del Valle, 2003: 44).

7. Sistema implantado en España desde 1986 (ibídem: 59). 
De forma que, como apunta Callejo (cf. 2001: 17), al enfrentarnos a una investigación empírica de audiencias estamos intentando analizar las relaciones entre una sociedad de consumidores, un grupo de medios de comunicación masivos (o dirigidos a receptores desconocidos) que buscan concentrar el máximo de minutos de consumo de televisión por parte del espectador, y una serie de anunciantes interesados en la proyección obtenida en esa sociedad a través de sus inversiones publicitarias en esos medios (aún cuando, en nuestro caso, este último punto no tiene incidencia desde la segunda temporada de "Águila Roja", al no emitirse publicidad comercial en TVE desde principios de 2010 como se ha apuntado).

\section{Análisis del caso de "Águila Roja"}

\subsection{La serie}

El género histórico está ganando amplio reconocimiento en la televisión española. “Águila Roja" ha impuesto la tendencia y le han seguido "Hispania, la leyenda" (Antena 3, de Bambú Producciones), "Isabel" (TVE, Diagonal TV), "Tierra de lobos" (Telecinco, de Multipark Ficción), "Toledo, cruce de destinos" (Antena 3, de Boomerang TV) o miniseries como "La princesa de Éboli” (Antena 3, de Antena 3 Films y Notro Televisión).

Personajes históricos o momentos concretos del pasado español se convierten en centro de interés, sin embargo la clave de la repercusión de "Águila Roja" es un pretexto altamente improbable en términos históricos ${ }^{8}$ : un héroe ficticio instruido en las artes ninjas en el siglo XVII español. Pilar Nadal, productora ejecutiva de la serie, reconoce que "en el origen de "Águila Roja” está la pretensión de dar un giro a toda la ficción televisiva del momento [...], era un reto y un riesgo porque no existía referencia en el mercado español que dijera cómo iba a reaccionar el público" (Vertele, 2011). A pesar de la incertidumbre sobre la acogida que tendría el producto, en Globomedia tenían unos objetivos claros: entretener y contar una historia en la corte de Felipe IV lo más pegada a la realidad posible, "para luchar contra la etiqueta que hace de la Historia algo duro de digerir dieron vida a un ficticio salvador del pueblo, un héroe justiciero, capaz de engatusar a todo el público" (Borreguero, 2010).

"Águila Roja" ha supuesto un punto y aparte en la producción de ficción en España y el interés de TVE al encargar una nueva serie a Globomedia no era otro que recuperar el target juvenil: en prime time ${ }^{9}$ su audiencia estaba muy envejecida, por ello le solicitó algo diferente. La serie que ha resultado ser finalmente "Águila Roja", donde se mezclan influencias tan dispares como la leyenda de Robin Hood, la literatura de Salgari y Dumas,

\footnotetext{
8. Precisamente una de las principales características que definen los productos de Globomedia, ya sean series o programas de entretenimiento, es la introducción de un tema o presentación del mismo distinta a cómo se había hecho hasta entonces ( $c f$. Bardají y Gómez, 2004: 166), en este caso la baza es un guerrero ninja como héroe justiciero en la España del siglo XVII.

9. Franja horaria que comprende en España entre las 20:30 y medianoche; también es conocida como "Noche I" (cf. Vaca, 2009: 30-31).
} 
entre otras, fue galardonada con el Premio Ondas 2010 al reconocer el jurado que recupera el género de aventuras y marca tendencia.

Con la entrada de las televisiones privadas en el panorama español, se produce un cambio de dinámica con respecto a la producción seriada precedente, viviendo una renovación que en el ámbito norteamericano se había dado varios años antes. Sirva de ejemplo cómo de las veinte series más vistas en 2007, trece fueron capítulos de producciones norteamericanas ("C.S.I. Las Vegas" y “C.S.I. Miami”) y el resto españolas (cinco “Aída” y una a "Cuéntame cómo pasó" y "Escenas de matrimonio"). El año anterior al estreno de "Águila Roja", 2008, es el del cambio ya que el dominio de la producción nacional se hace pleno: las veinte emisiones del ranking correspondieron a series españolas, con un capitulo de "Yo soy Bea", la versión española de "Betty la fea", a la cabeza (Panorama Audiovisual, 2010). En este entorno se presenta, al año siguiente, la innovadora serie de Globomedia objeto de nuestra investigación.

Tras su máscara de novedad, “Águila Roja” responde al esquema habitual de las series de su productora que podemos resumir en los siguientes puntos ( $c f$. Bardají \& Gómez, 2004: 165-166):

- Estructura narrativa sostenida por cuatro tramas: una principal, dos secundarias y una última cómica. El desarrollo de todas ellas persigue atrapar la atención del espectador hasta el final del capítulo.

- Hibridación de géneros bajo el arco de una nueva categoría (la dramedia) ${ }^{10}$.

- Vocación hacia la audiencia familiar y adaptación de ciertos elementos para ajustarse a un amplio abanico de generacional de espectadores (especialmente por el lenguaje contemporáneo que presenta la producción, alejado intencionadamente del usado en el Siglo de Oro). Las tramas se diseñan para satisfacer todos los gustos, sea cual sea la edad del espectador, y el reparto tiene una gran amplitud en cuanto a la edad los personajes (y en consecuencia de los intérpretes).

- Capítulos semanales que exceden ampliamente la hora de duración (oscilan entre los setenta y ochenta minutos) ${ }^{11}$.

- Las tramas episódicas se diseñan acordes con el contexto cronológico, de tal manera que hasta ahora se han visto sucederse epidemias, torturas, diversas supersticiones, la inquisición, entre otros recursos "históricos".

La serie arranca con una tragedia que provoca el nacimiento del héroe: Gonzalo de Montalvo (David Janer), maestro de escuela, ve morir a su esposa. Se embarca en la

10. Combinación del "drama” y la "tragedia".

11. Se trata de un fenómeno español y único en el mundo: las series en prime time tienen esa media de duración, mientras que en Estados Unidos, por ejemplo, rondan los cuarenta minutos, una hora como mucho (cf. Abril, 2010: 54). 
búsqueda de los culpables y vengarse, para ello adoptará una identidad secreta: Águila Roja, justiciero social con motivaciones personales. Los únicos que conocen su doble condición son su mano derecha, Sátur (Javier Gutiérrez) y un misterioso monje, Agustín (Adolfo Fernández), que ejerce de maestro y vigilante de los pasos del héroe.

El resto de personajes desconocen su doble vida, desde su hijo Alonso (Guillermo Campra), quien ve a su padre como un cobarde mientras no esconde su admiración por Águila Roja, hasta su cuñada Margarita (Inma Cuesta) con la que vivió una historia de amor juvenil que parece renacer con su vuelta, sirviendo así una trama romántica. Todo héroe tiene su antagonista y este es Hernán Mejías, comisario de la Villa (Francis Lorenzo), al que acompañan otros dos personajes oscuros: la intrigante Lucrecia, marquesa de Santillana (Miryam Gallego), y el cardenal Mendoza, obsesionado con alcanzar el papado (José Ángel Egido).

Las temporadas se han vertebrado a partir de una serie de líneas argumentales distintas: la primera ha girado alrededor de la lucha del protagonista frente una logia conspirativa contra el rey, Felipe IV, y sus pesquisas para esclarecer las circunstancias de la trágica muerte de su esposa. La segunda y tercera se constituyen a partir de la obsesión de Gonzalo por descubrir sus verdaderos orígenes tras serle revelado al final de la primera temporada que su hermano es realmente el comisario. La cuarta, y última emitida hasta ahora, pierde un poco de pulso al dotar de mayor protagonismo a las tramas episódicas, de manera que se pierde la vertebración y unidad sobre un tema común que ha caracterizado a las temporadas anteriores.

\subsection{Análisis cuantitativo de la audiencia}

\subsubsection{La situación de la serie con respecto al resto de producción seriada española}

"Águila Roja" ha sido habitual líder en los rankings de audiencia desde su estreno, haciéndose más relevante desde la segunda temporada. Su programación, a lo largo de todas las temporadas no ha sido fija en un único día, así que se ha visto los jueves ${ }^{12}$ en las emisiones entre febrero de 2009 y noviembre de 2010, y los lunes en las comprendidas entre septiembre de 2011 y enero de $2012^{13}$, en todos los casos conservando su posición en la franja de prime time, con emisiones iniciadas hacia las 22:15 y concluidas a las 23:45 aproximadamente.

Desde la segunda temporada “Águila Roja” encabeza la lista de las catorce series españolas; tomemos para observar la posición de la serie respecto a las producciones nacionales más

\footnotetext{
12. Día preferente para TVE para colocar sus series estrella. De hecho, el cambio de la serie a los lunes, dejando el jueves (donde se posicionó la veterana "Cuéntame cómo pasó"), provocó no pocas incertidumbres sobre el mantenimiento del impacto entre la audiencia.

13. En el lapso de tiempo entre noviembre de 2010 y septiembre de 2011 , se estrenó una adaptación de la serie para la gran pantalla concebida como un gran episodio que mantiene la calidad técnica que caracteriza a esta producción y no plantea ninguna ruptura narrativa con su origen: Águila Roja, la película (2011), dirigida por José Ramón Ayerra Díaz.
} 
seguidas la temporada 2010-2011 (periodo correspondiente a la emisión de la primera parte de la tercera temporada) donde continúa encabezando el listado, con una diferencia de más de un millón cien mil espectadores y un $6.3 \%$ de cuota de pantalla respecto a la segunda, "Cuéntame cómo pasó", también de TVE, tal como se muestra en la siguiente tabla:

Figura 1: Series españolas más vistas 2010-2011.

\begin{tabular}{|c|c|c|c|c|}
\hline SERIE & CANAL & EMISIONES & $\mathrm{AM}(000)$ & SHARE \\
\hline "Águila Roja" & La 1 & 7 & 5832 & $30.1 \%$ \\
\hline "Cuéntame cómo pasó" & La 1 & 17 & 4723 & $23.8 \%$ \\
\hline "El barco" & Antena 3 & 13 & 4140 & $20.6 \%$ \\
\hline "Hispania, la leyenda" & Antena 3 & 17 & 3624 & $19.2 \%$ \\
\hline "14 de abril. La República" & La 1 & 13 & 3516 & $17.1 \%$ \\
\hline "Gran Reserva" & La 1 & 13 & 3480 & $18.4 \%$ \\
\hline "Aída" & Telecinco & 28 & 3151 & $16.7 \%$ \\
\hline "Los misterios de Laura" & La 1 & 12 & 3079 & $16.3 \%$ \\
\hline "Los protegidos" & Antena 3 & 14 & 3025 & $15.1 \%$ \\
\hline "Las chicas de oro" & La 1 & 25 & 2925 & $14.8 \%$ \\
\hline "Tierra de lobos" & Telecinco & 13 & 2.842 & $15,9 \%$ \\
\hline "La que se avecina" & Telecinco & 12 & 2.793 & $15,8 \%$ \\
\hline "Amar en tiempos revueltos" & La 1 & 218 & 2.783 & $21,8 \%$ \\
\hline "El internado" & Antena 3 & 7 & 2.670 & $14,9 \%$ \\
\hline
\end{tabular}

Fuente: Martín (2011).

Ninguno de los trece capítulos de la primera temporada logra situarse entre las cincuenta emisiones más vistas de 2009: un listado monopolizado por las retransmisiones deportivas (partidos de fútbol en su integridad), en donde las únicas ficciones seriadas son dos capítulos de "23F: el día más difícil del Rey" (TVE) (puestos 16 y 25) y uno de "Aída" en el 46 ( $c f$. Barlovento, 2010: 21). En 2010, con la emisión de los primeros siete capítulos de la tercera ${ }^{14}$, logra situar tres de ellos entre la cincuentena de emisiones más seguidas del año. Realmente se trata de la única ficción que aparece en un ranking dominado, como el del año anterior, por los espacios futbolísticos ${ }^{15}$.

14. Se distribuyen así: capítulo 7, puesto 37; capítulo 6, en el 45; y el capítulo 3, situado en el 49 (Barlovento, 2011: 21).

15. En 2010 se celebró el Mundial de Fútbol en Sudáfrica. 
Situación pareja volvemos a encontrar en la lista de lo más visto de 2011, con la diferencia de que diez de las emisiones son episodios de "Águila Roja", la única de ficción que halla hueco entre las deportivas, la votación de Eurovisión y las de la segunda edición del "Telediario" de TVE"16. Entre las veinte emisiones más seguidas de 2012, ninguna de ellas corresponde a un capítulo de "Águila Roja”, estando monopolizada la clasificación por los espacios deportivos (retransmisiones de fútbol de la Eurocopa) y tan sólo se cuelan tres espacios informativos.

Finalmente, para dar otra perspectiva más y situar el impacto de la serie en el entorno de la ficción seriada española, y específicamente en el ámbito de las audiencias, comprobemos también cómo durante tres años consecutivos, de 2010 a 2012, “Águila Roja” coloca uno de sus capítulos como el más visto del año en términos de audiencia media en esta gráfica histórica que arranca en 2002, dando una perspectiva de diez años (figura 2), manteniéndose en los niveles habituales de los últimos siete años (alrededor de los seis millones y medio de espectadores) junto a "Aída”, “Aquí no hay quien viva” y “23F: El día más difícil del Rey”:

Figura 2: Capítulo más visto del año.

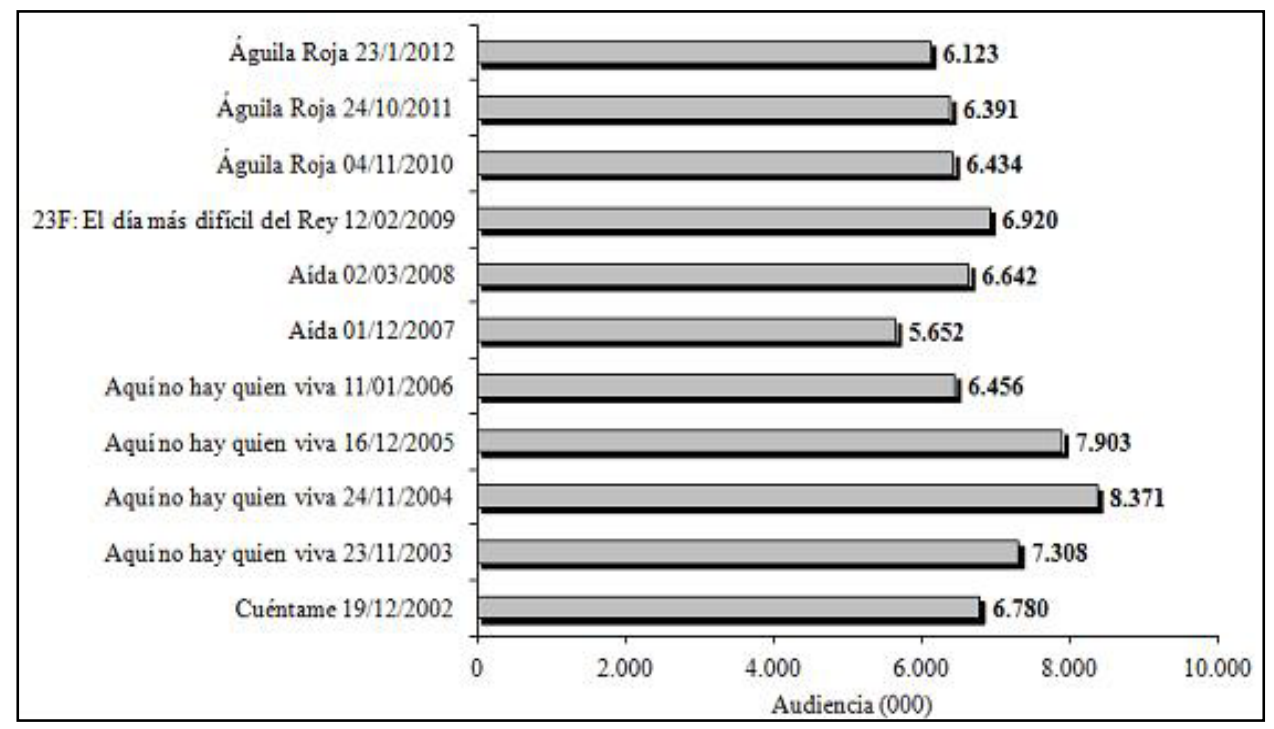

Fuente: Vaca (2009: 129) y Barlovento Comunicación (2010-2013).

16. Se distribuyen así: episodio 2 de la cuarta: puesto 29; primero de la cuarta: en el 31; el noveno, cuarto y sexto: puestos 34, 35 y 36 respectivamente; el quinto y el octavo se sitúan en el 38 y 39; el trece y el doce de la tercera, en el 42 y 43; y la lista cierra con el once de la tercera, en el 50 (Barlovento, 2012: 21). 


\subsubsection{El comportamiento de la audiencia de "Águila Roja” (temporadas y episodios)}

El gran triunfo de la serie de Globomedia ha sido que TVE haya recuperado un sector de audiencia que le había abandonado en prime time: el juvenil. Es una de las razones por las que la cadena pública planteó un proyecto de estas características a la productora, como hemos señalado antes. Los datos son elocuentes ${ }^{17}$, con una media del $22 \%$ en todos los targets juveniles (que se engloban genéricamente, en la figura 3, en el grupo entre 13 y 24 años), aunque sigue pesando el bloque de espectadores con edad superior a 65 años, uno de los pilares tradicionales de TVE, donde seduce a casi un tercio de la audiencia de ese tramo. En relación al género, la serie tiene una ligera preferencia entre el público femenino: hombres, $26 \%$ y mujeres, $26.7 \%$.

Figura 3: Distribución de audiencia por edades.

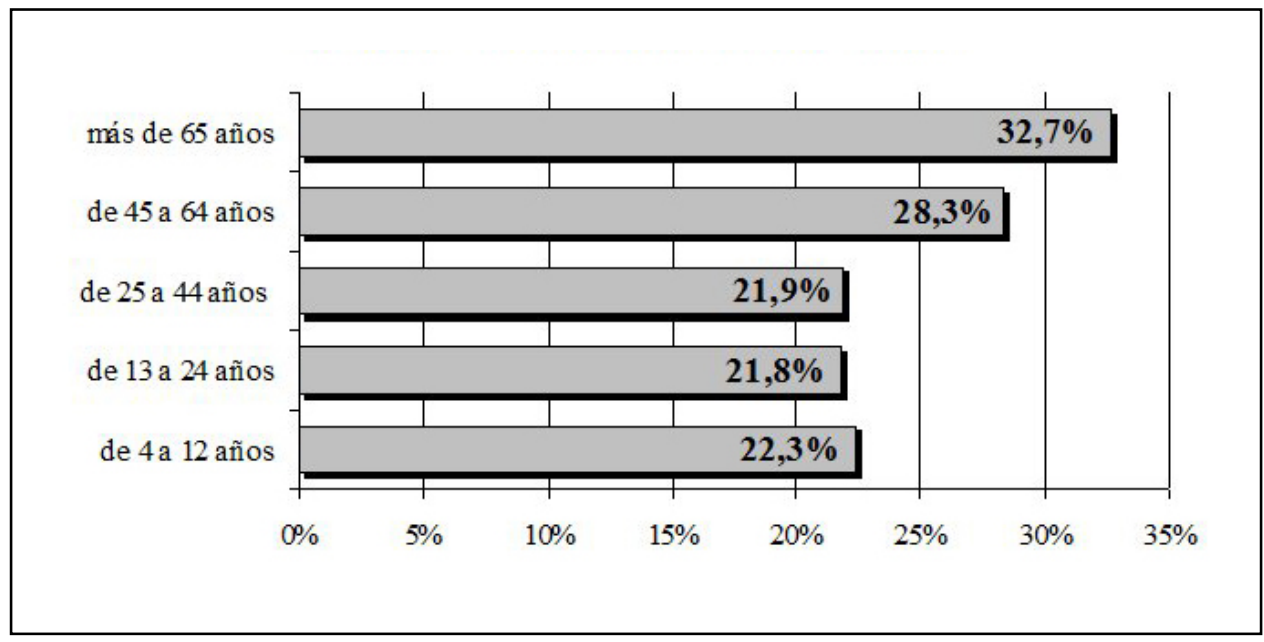

Fuente: Elaboración propia, basada en Fórmula TV (2009a).

Con el propósito de ir centrándonos en el devenir y progresión de las distintas temporadas, para comparar y contextualizar estos datos, se presentan en los siguientes gráficos las medias de audiencia (figura 4) y cuota de pantalla global por temporadas (figura 5):

17. Estos datos aún están lejos de otras series como "Los hombres de Paco", con 33,6\% entre jóvenes de 13 a 24 o HKM con 20,7\% entre jóvenes de 13 a 24 (Fórmula TV, 2009a). 
Figura 4: Audiencia media por temporadas.

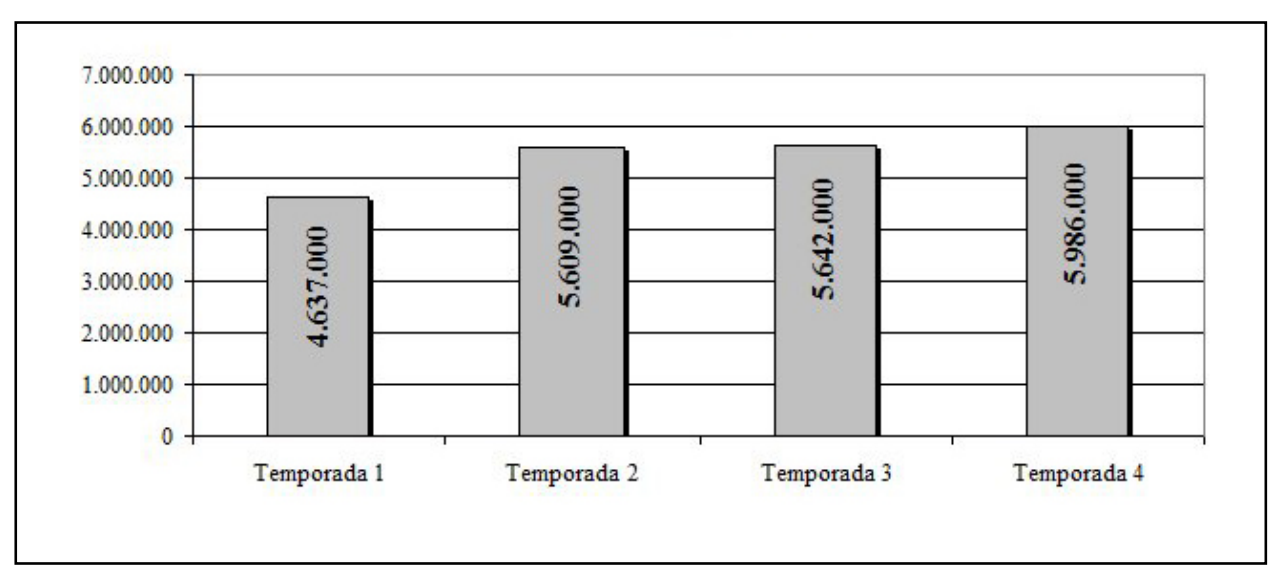

Fuente: Elaboración propia.

Como se observa en la figura 4, de la primera a la segunda temporada la serie gana una media de 972000 espectadores, aumento que es más mucho menor la segunda a la tercera, siendo de 33 000, y de esta última a la cuarta gana 344 000. En cuanto al share, en la figura 5 , la diferencia sí es más notoria de la primera a la segunda, donde asciende 2.8 puntos, mientras que posteriormente los incrementos se moderan visiblemente: de la segunda a la tercera son 1,04 puntos, y de la tercera a la cuarta 0.21 . De forma que el acumulado de la primera a la cuarta temporada arroja las siguientes cifras: una ganancia media de 1349000 espectadores y un $4.05 \%$ de cuota de pantalla.

Figura 5: Media de share por temporada.

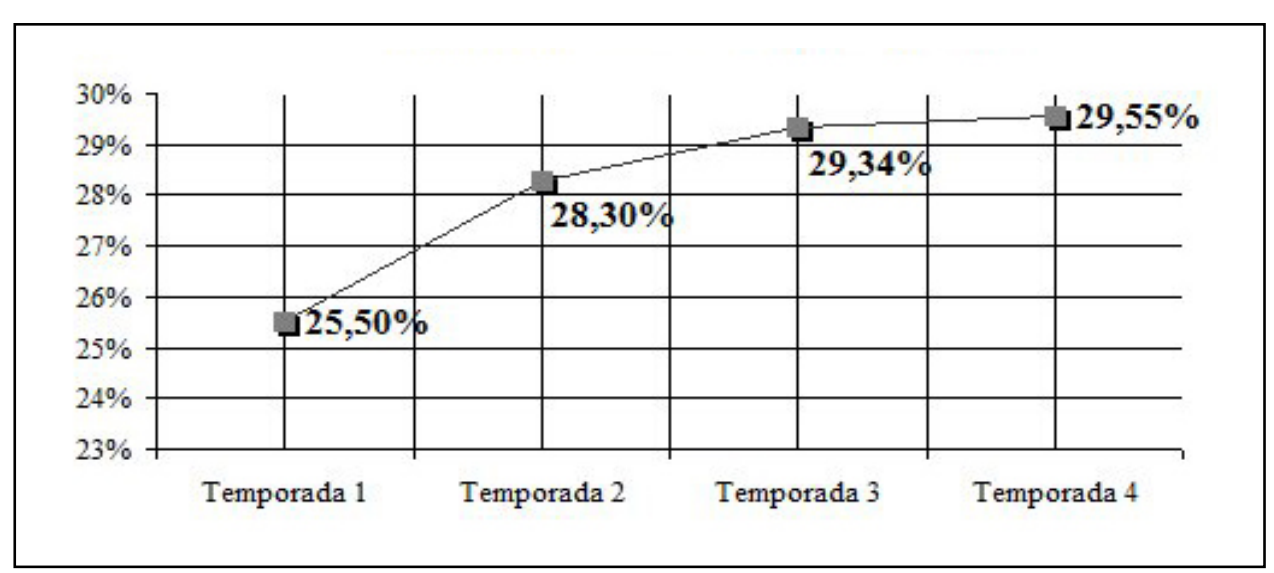

Fuente: Elaboración propia. 
Para contextualizar los datos que se están aportando, hay que señalar que la primera temporada se emitió con publicidad ${ }^{18}$, la segunda, tercera y cuarta no ${ }^{19}$, lo que puede verse como un factor a tener en cuenta en el impulso de los números obtenidos por las tres últimas temporadas, tal y como se refleja en la figura 6, donde tanto la segunda como la tercera y cuarta sobrepasan en todos los capítulos los datos de la primera (salvo el ocho de la tercera, el arranque de la segunda parte de la tercera temporada a principios de septiembre de 2011, con 4674000 espectadores, y el tercero de la cuarta, emitido el día anterior al festivo de primero de noviembre de 2011, viéndose evidentemente afectado por tal circunstancia). Igualmente las temporadas se han emitido en diferentes épocas del año, la primera (trece capítulos) entre el 19 de febrero y el 21 de mayo de 2009, la segunda (trece episodios) del 7 de enero al 8 de abril de 2010, la primera parte de la tercera (siete entregas) fue vista entre el 23 de septiembre y el 4 de noviembre de 2010, y la segunda parte de la tercera (seis capítulos) y la primera de la cuarta (doce episodios), se emitieron continuadas entre el 5 de septiembre de 2011 y el 23 de enero de 2012 (excepto los lunes que coincidieron con el periodo navideño):

Figura 6: Audiencia media por capítulos.

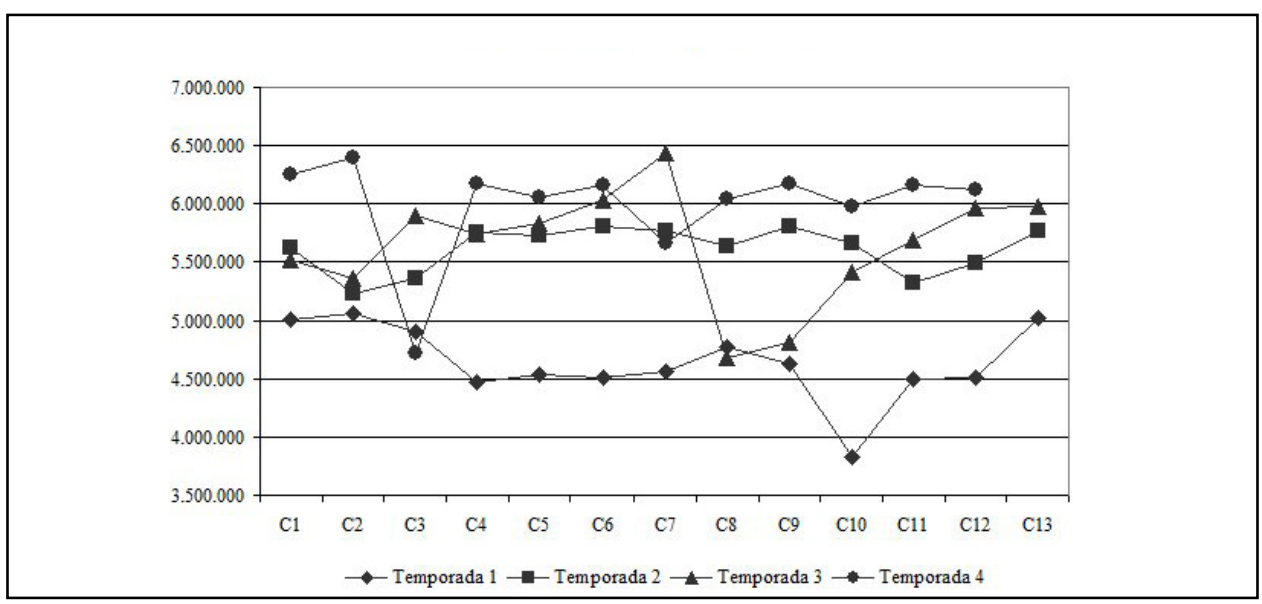

Fuente: Elaboración propia, basada en datos diarios de audiencia.

Como se muestra en la figura 6, en la evolución de la audiencia de la primera a la cuarta temporada, se observa claramente cómo la serie comenzó su andadura con una abultado número de espectadores, sobrepasando los cinco millones, se trata del mejor arranque de ficción en España desde 2005 (Fórmula TV, 2009b), con fluctuaciones a la baja hasta alcanzar un pico mínimo de 3827000 en el capítulo diez ("La unión hace la fuerza",

18. Alrededor de unos 7 minutos de spots por episodio.

19. En virtud de la aplicación de la Ley 8/2009, de 28 de agosto, de financiación de la Corporación de Radio y Televisión Española, puesta en marcha el 1 de enero de 2010. 
primera parte de los dos episodios dedicados al asesino de niños; de hecho, este episodio es el mínimo histórico alcanzado por "Águila Roja”), cerrando temporada con unos datos en los que recuperaba los iniciales.

La audiencia de la segunda oscila entre un máximo de más de 5800000 de la sexta entrega ("Intento de asesinato en palacio", con la tentativa de asesinato del inquisidor general y descubrimiento de un grupo de profanadores de tumbas) y un mínimo de 5231000 en el capítulo dos ("Águila Roja continúa su búsqueda", con el descubrimiento por parte del héroe de una pista decisiva de su pasado: un medallón que su madre cita en una carta). En el caso de la emisión de la tercera, los datos arrojan un máximo de espectadores para la temporada y al mismo tiempo un techo histórico para la serie en el episodio siete ("Un misterioso castillo", donde Águila Roja encuentra el torreón en el que estuvo encerrado con su madre y su hermano cuando era tan sólo un niño), con 6434000 espectadores de media ante el televisor viendo el desarrollo del capítulo, y un mínimo de 4674000 en la octava entrega ("Muertes y engaños", donde la contaminación del agua del río que surte a la Villa amenaza con acabar con sus habitantes), con el que la serie regresa a la pantalla tras un año de ausencia, a principios de septiembre de 2011, todavía bajo el influjo de los horarios y costumbres estivales ${ }^{20}$.

Respecto a la cuarta temporada, su máximo lo alcanza con el capítulo dos ("Los niños del hospicio", donde los huérfanos del orfanato empieza a desaparecer misteriosamente y se descubre que la marquesa, desaparecida, está en realidad enterrada en una caja), que se convierte en el segundo más visto en la historia de “Águila Roja”, con 6391000 espectadores. El mínimo del ciclo llega en el siguiente, con el tercer episodio ("La confirmación de Nuño", donde Águila Roja y Sátur investigan la desaparición de mujeres a punto de dar a luz), con 4717000 espectadores, cifra más habitual en la primera temporada.

A partir de este, la progresión en audiencia media de los capítulos que restan de temporada es sostenida alrededor de los seis millones cien mil espectadores, con las excepciones de los capítulos siete ("La marquesa de marcha a Viena", donde Sátur sufre cautiverio por parte de su maléfico gemelo mientras la marquesa y su séquito emprenden viaje a la corte vienesa) y diez ("El Duque de Alba llega a la Villa", en el que Sátur salva al aristócrata de unos bandoleros y este le propone que trabaje para él), con 5661000 y 5937000 seguidores respectivamente. El primero de ellos es emitido la víspera de los festivos de comienzos de diciembre y el segundo es el del regreso tras el receso navideño.

Si ordenamos los capítulos en relación a la audiencia media alcanzada, los primeros puestos vienen protagonizados visiblemente por los de la tercera y cuarta temporadas, mientras que los de la primera son los que registran los datos más discretos (salvo algunas excepciones ya comentadas).

20. Otro factor a tener en cuenta es que el capítulo fue estrenado por error en Clan TV, en la madrugada del 22 de junio de 2011, circulando a las pocas horas múltiples copias por Internet. 
En relación a la comparativa de la cuota de pantalla por episodios, tal como se muestra en la figura 7, los datos van en progresión ascendente salvo algunas fluctuaciones; el mínimo histórico en todas las temporadas lo ofrece el capítulo diez de la primera temporada ("La unión hace la fuerza"), coincidiendo con el suelo de audiencia media visto en el gráfico anterior, con un $22.9 \%$ de share en este caso. El máximo viene de nuevo con el séptimo episodio de la tercera temporada ("Un misterioso castillo"), con un histórico techo de $32.5 \%$ (se trata de la primera serie en alcanzar este dato en España desde marzo de 2008).

Figura 7: Share por capítulos.

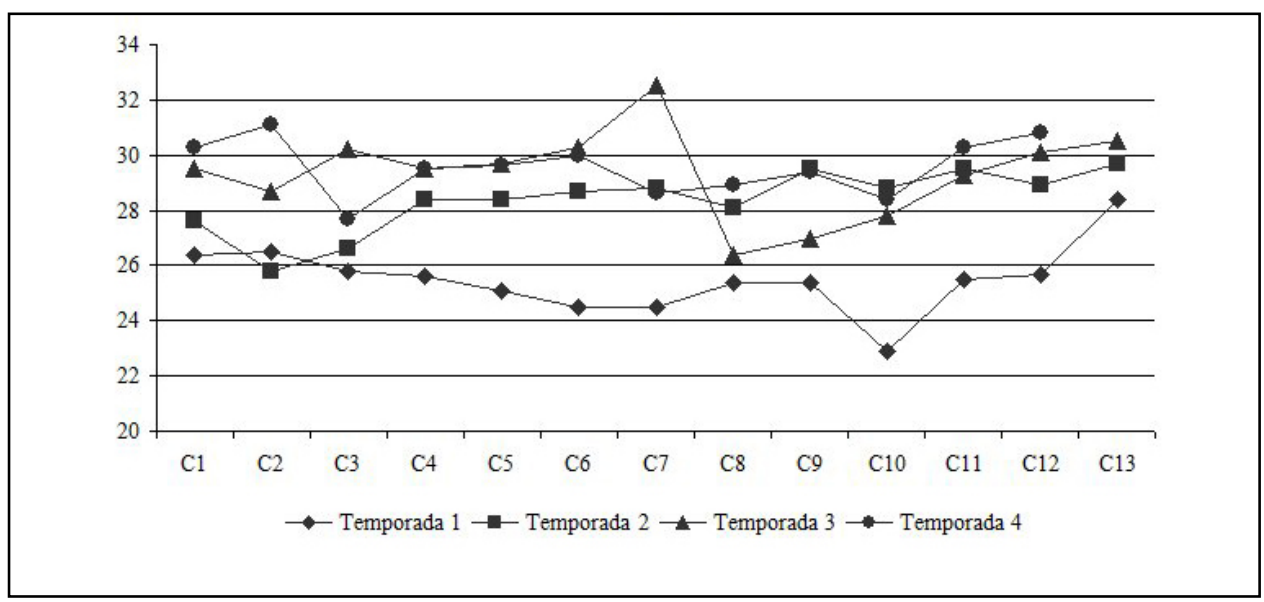

Fuente: Elaboración propia, basada en datos diarios de audiencia.

Si volvemos a ordenar los capítulos pero en esta ocasión por cuota de pantalla alcanzada, vemos cómo de nuevo los puestos de cabecera son de capítulos de la tercera y cuarta temporadas, y los situados al final corresponden a la primera. Con el tercer episodio de la tercera temporada ("Difíciles momentos para la marquesa"), “Águila Roja" supera por primera vez en su historia la barrera psicológica del 30\% de share, volviéndolo a repetir con otros nueve capítulos de la tercera y cuarta temporadas.

Para aportar otra perspectiva, veamos otra tabla (figura 8) donde se contrastan los datos de los capítulos inicial y final de temporada ${ }^{21}$. La primera temporada gana 13000 espectadores y sube dos puntos en la cuota de pantalla, en la segunda son 100000 más y un incremento del $2.1 \%$ en cuanto a share, mientras que en la tercera los datos arrojan un diferencial

21. Se ha optado por esta fórmula con la intención de mantener la estructura de análisis (por temporadas) que se ha elegido para la investigación; sin embargo, si atendemos a los ciclos de emisión (donde se han separado y agrupado temporadas), los resultados para la tercera y cuarta son diferentes: $3^{\mathrm{a}}$ temporada $\left(1^{\mathrm{a}}\right.$ parte): estreno (23/09/2010): 5523000 y 29.5\%; final (4/11/2010): 6434000 y 32.5\%; diferencial: incremento de 911000 espectadores y $3 \%$ de share. $3^{\mathrm{a}}$ temporada ( $2^{\mathrm{a}}$ parte) y $4^{\mathrm{a}}\left(1^{\mathrm{a}}\right.$ parte): estreno (05/09/2011): 4674000 y $26.4 \%$; final (23/01/2012): 6123000 y 30.8\%; diferencial: aumento de 1449000 espectadores y 4.4\% de share. 
más abultado: asciende en 448000 espectadores y un punto más de audiencia relativa. En relación a la cuarta, la audiencia media arroja datos negativos: una pérdida de 126000 espectadores entre el primer y último capítulo, aunque la audiencia relativa sube medio punto porcentual. De forma que la serie, en el diferencial desde su inicio en febrero de 2009 hasta el último capítulo hasta la fecha, emitido en enero de 2012, presenta una ganancia en audiencia media de 1110000 espectadores y un ascenso del 4.4\% de share:

Figura 8: Diferencial inicio-final de temporadas.

\begin{tabular}{|c|c|c|c|}
\hline TEMPORADA 1 & EMISIÓN & $\mathbf{A M}$ & SHARE \\
\hline Estreno & $19 / 02 / 2009$ & 5013000 & $26.4 \%$ \\
\hline Final & $21 / 05 / 2009$ & 5026000 & $28.4 \%$ \\
\hline \multicolumn{2}{|l|}{ Diferencial } & + 13000 & $+2 \%$ \\
\hline TEMPORADA 2 & EMISIÓN & $\mathbf{A M}$ & SHARE \\
\hline Estreno & 07/01/2010 & 5622000 & $27.6 \%$ \\
\hline Final & 08/04/2010 & 5722000 & $29.7 \%$ \\
\hline \multicolumn{2}{|l|}{ Diferencial } & +100000 & $+2.1 \%$ \\
\hline TEMPORADA 3 & EMISIÓN & $\mathbf{A M}$ & SHARE \\
\hline Estreno & $23 / 09 / 2010$ & 5523000 & $29.5 \%$ \\
\hline Final & $10 / 10 / 2011$ & 5971000 & $30.5 \%$ \\
\hline \multicolumn{2}{|l|}{ Diferencial } & +448000 & $+1 \%$ \\
\hline TEMPORADA 4 & EMISIÓN & $\mathbf{A M}$ & SHARE \\
\hline Estreno & $17 / 10 / 2011$ & 6249000 & $30.3 \%$ \\
\hline Final & $23 / 01 / 2012$ & 6123000 & $30.8 \%$ \\
\hline \multicolumn{2}{|l|}{ Diferencial } & -126000 & $+0.5 \%$ \\
\hline
\end{tabular}

Fuente: Elaboración propia.

En todos sus días de emisión, tanto lunes como jueves, "Águila Roja” monopoliza el minuto de oro del día ${ }^{22}$; véase cómo la figura 9 muestra la evolución al respecto en las cuatro temporadas:

22. También conocido como audiencia máxima, "dado un período o franja de tiempo determinado [...] es el número total de individuos estimados en el instante de mayor audiencia" (Jauset, 2000: 239). 
Figura 9: Audiencia máxima por capítulos.

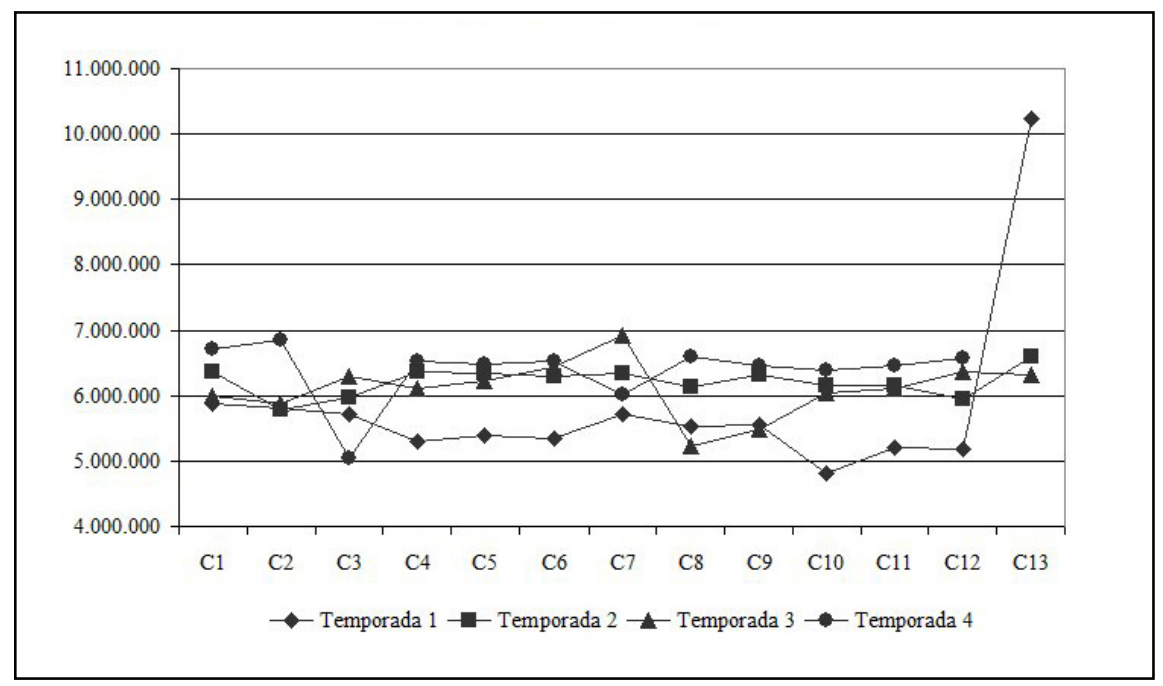

Fuente: Elaboración propia, basada en datos diarios de audiencia.

Como se observa, hay un pico notoriamente destacado, evidencia de la disparada cifra alcanzada por el último episodio de la primera temporada ("Lucha a muerte entre el comisario y Águila Roja"), con más de diez millones de espectadores reunidos en el momento en que Agustín descubre al héroe que el comisario es su hermano. La diferencia con el siguiente minuto de oro más visto de la serie es abultada (más de tres millones), y de nuevo coincide con un cierre de temporada (en este caso, el de la primera parte de la tercera: "Un misterioso castillo"), donde una audiencia de 6913000 espectadores veía cómo el comisario le hace una declaración de amor a Lucrecia tras arrojarla al río. El mínimo histórico se sitúa en el décimo de la primera temporada ("La unión hace la fuerza"), con menos de cinco millones.

La mayor parte de los capítulos cotizan su minuto de oro sobrepasando los seis millones de espectadores (de 51 emitidos, 20 de ellos quedan por debajo). La lectura de los datos de audiencia máxima nos permite señalar los minutos de oro líderes de las temporadas dos y cuatro; con respecto a la primera de ellas, se debe al capítulo trece, cierre de temporada ("Gonzalo, a punto de abandonar su búsqueda"), cuando 6587000 espectadores contemplaban el reencuentro entre Margarita y su esposo, a quien creía fallecido. En cuanto a la última temporada emitida hasta ahora, la cuarta, su audiencia máxima la alcanza con la segunda entrega ("Los niños del hospicio"), reuniendo a 6840000 individuos con la confesión de Sátur: ha apostado la casa de Gonzalo a las cartas y la ha perdido.

Queda fuera del marco de la investigación que nos hemos propuesto, pero no se querría dejar de lado que "Águila Roja" es accesible también a través de otras plataformas tecnológicas al margen de la Televisión Digital Terrestre. Como indica Morales (2011), "por sus características nativas el discurso de ficción ostenta distintas ventajas que lo hacen particularmente atractivo 
para capitalizar satisfactoriamente las nuevas ventajas del consumo televisivo en el entorno digital. La ficción puede emitirse por la TDT o por dispositivos personales. Se adapta bien al consumo individual o grupal. Posee un formato serial y desarrolla relatos atemporales que facilitan su ajuste a distintos mercados y públicos”.

En este sentido, por la cobertura que ha llegado a alcanzar, Internet ${ }^{23}$ se ha convertido en una pantalla alternativa al televisor y apunta un extraordinario crecimiento entre las audiencias jóvenes, las cuales dedican muchas horas al visionado y descarga de episodios íntegros a través de la red. En este ámbito "Águila Roja" es una de las series preferidas de los internautas españoles junto a "La que se avecina" y "Aída", de hecho figura como la segunda más bajada y la favorita en visionado en streaming entre las nacionales en 2011 (Lainformación.com, 2011).

\section{Conclusiones}

Cuando “Águila Roja” llegó a la pequeña pantalla en febrero de 2009, se encontró con un terreno abonado y favorable, por parte de la audiencia, hacia las producciones seriadas españolas, las cuales desde el año anterior monopolizaban las veinte emisiones de series más vistas en España, desplazando a la producción extranjera y esencialmente a la norteamericana.

El notable incremento de audiencia media y cuota de pantalla que desplegó la serie en su segunda temporada respecto a la primera, sosteniéndose e incrementándose en las siguientes, la situó en 2010 y 2011 a la cabeza del listado de las ficciones televisivas nacionales más seguidas, así como varios de sus capítulos se colocan entre las cincuenta emisiones más vistas del año: en 2010 son tres y en 2011 diez. A ello se suma que uno de los episodios de la serie de Globomedia es el más visto de la ficción seriada española tanto en 2010 (séptimo de la tercera temporada) como en 2011 (segundo de la cuarta), manteniendo los habituales datos de espectadores registrados en los últimos seis años.

La evolución de la audiencia media y share por temporadas revela una progresión en la que se acrecientan ambos referentes: el acumulado arroja una ganancia media de 1349000 espectadores y un $4.05 \%$ de cuota de pantalla. El salto es mayor de la primera a la segunda temporada, a partir de esta se mantiene el incremento aunque los valores se suavizan. En lo que respecta a estos indicadores de audiencia por capítulos, queda marcado un techo de 6 434000 espectadores con el capítulo siete de la tercera temporada y, en el extremo opuesto, el menos seguido es el décimo de la primera temporada con 3827 000. Los mejores datos de audiencia se dan con los capítulos de las temporadas tercera y cuarta, de forma sostenida salvo algunas excepciones. De los cincuenta y uno episodios emitidos hasta enero de 2012, diez de ellos sobrepasan el $30 \%$ de cuota de pantalla.

23. Muchas cadenas de televisión han optado por potenciar sus alojamientos web para facilitar el visionado de los episodios de sus series. Tal es el caso de "Águila Roja” y su página oficial, donde se ofrece acceso online a todos sus capítulos, junto a otro tipo de contenidos. 
En cuanto al minuto de oro del día que en que se emite "Águila Roja”, logra monopolizarlo en todas sus entregas de estreno en $L a 1$ de TVE, alcanzando su techo con el cierre de la primera temporada, con 10244000 espectadores, y el mínimo se sitúa con el décimo, también de la primera, con menos de cinco millones. La comparativa entre el capítulo uno y el de cierre de cada una de las temporadas arroja números positivos salvo en la cuarta; sin embargo, el diferencial entre el primero y el cincuenta y uno sí aporta valores positivos: 1110000 espectadores más de media y un incremento del $4.4 \%$ en la cuota de pantalla.

La ficción de Globomedia, ya sea emitida los lunes o los jueves, ha sido capaz de barrer a las ofertas de la competencia, sean partidos de fútbol, reality shows, programas dedicados a fenómenos mediáticos o escándalos judiciales. Así, con “Águila Roja”, TVE cumple uno de sus objetivos al contratar la serie con Globomedia: recupera el target juvenil en prime time, con una media del $22 \%$ en todos sus tramos de edad, y en cuanto al género muestra una ligera preferencia entre el público femenino.

\section{Fuentes consultadas}

Abril, G. (2010, diciembre 12). “La serie reina”. El País, suplemento “El País semanal”, pp. 42-54.

Bardají, J. y Gómez Amigo, S. (2004). La gestión de la creatividad en televisión. El caso de Globo Media. Pamplona: EUNSA.

Barlovento Comunicación.

_(2013). Análisis televisivo 2012. Madrid: Barlovento Comunicación.

_(2012). Análisis televisivo 2011. Madrid: Barlovento Comunicación.

_(2011). Análisis televisivo 2010. Madrid: Barlovento Comunicación.

_(2010). Análisis televisivo 2009. Madrid: Barlovento Comunicación.

Borreguero, M. (2010). “¿Qué hace un Ninja en el siglo XVII español? Garantizar el éxito de 'Águila Roja”". Extraída el 14/I/2013 desde http://noticias.lainformacion.com/artecultura-y-espectaculos/television/que-hace-un-ninja-en-el-siglo-xvii-espanol-garantizarel-exito-de-aguila -roja_Y01HQ2pAMwjBW0FGAXntv5/

Callejo, J. (2001). Investigar las audiencias. Un análisis cuantitativo. Barcelona: Paidós.

Fórmula $T V$, portal web.

_(2009a, febrero 20). "La 1 se reencuentra con el público juvenil gracias a 'Águila roja"”. Extraída el 19/II/2014 desde http://www.formulatv.com/noticias/10447/la-1-sereencuentra-con-el-publico-juvenil-gracias-a-aguila-roja/

_(2009b, marzo 5). "David Janer: 'La ambientación de Águila Roja es una excusa estética, no entiendo las críticas"”. Extraída el 7/I/2013 desde http://www.formulatv.com/ 1,20090305,10592,1.html 
González del Valle, A. (2003). "Medición de audiencias de televisión en España. Una perspectiva histórica”, pp. 43-55. En Igartua, J. y Badillo, A. (eds.). Audiencias y medios de comunicación. Salamanca: EUNSA.

Huertas Bailén, A. (2002). La audiencia investigada. Barcelona: Gedisa.

Igartua, J. y Badillo, A. (eds.) (2003). Audiencias y medios de comunicación. Salamanca: EUNSA.

Jauset, J.

_(2003). "La investigación de mercados, audiencias y estadística", pp. 57-65. En Igartua, J. y Badillo, A. (eds.). Audiencias y medios de comunicación. Salamanca: EUNSA.

_(2000). La investigación de audiencias en televisión. Fundamentos estadísticos. Barcelona: Paidós.

Lainformación.com (2011, septiembre 26). “'House', 'La que se avecina' y 'Águila roja', las series con más tirón en Internet”. Extraída el 20/II/2014 desde http://noticias. lainformacion.com/arte-cultura-y-espectaculos/television/house-la-que-se-avecina -y-aguila-roja-las-series-con-mas-tiron-en-internet_AJApoe9O1FID8hnHj3s6j/

Martín, L. (2011, julio 18). “Las series españolas más vistas de la temporada 2010-2011”. En blog El Rincón de Lalo. Extraída el 5/III/2014 desde http://premiosdelpublicotv. blogspot.com/ 2011/07/las-series-espanolas-mas-vistas-de-la.html

Morales Morante, L. (2011). "Entre la TDT y el ordenador. Nuevas tendencias tecnológicas, empresariales y de consumo alrededor de la ficción audiovisual en España". Vivat Academia, núm. 114. Extraída el 14/I/2013 desde http://www.academia.edu/496663/ Entre_la_TDT_y_el_ordenador_nuevas_tendencias_tecnologicas_empresariales_y_de_ consumo_alrededor_de_la_ficcion_audiovisual_en_Espana

Morley, D. (1996). Televisión, audiencias y estudios culturales. Buenos Aires: Amorrortu Editores.

Orozco Gómez, G. (2001). Televisión, audiencias y educación. Buenos Aires: Grupo Editorial Norma.

Panorama audiovisual 2008-2009 (2010). Madrid: Entidad de Gestión de Derechos de los Productores Audiovisuales (EGEDA).

Planas, P. (2003). “Televisión y audiencias en el digital ¿quién mandará en los contenidos?”, pp. 85-98. En Igartua, J. y Badillo, A. (eds.). Audiencias y medios de comunicación. Salamanca: EUNSA.

RTVE televisión (2014). Página oficial de “Águila Roja”. Extraída el 20/II/2014 desde http://www.rtve.es/television/aguila-roja/ 
Vaca Berdayes, R. (2009). El puzzle de la audiencia televisiva. Madrid: Fundación Ex Libris.

Vertele (2011, julio 5). “Sabía que el primer capítulo de Águila Roja no gustó y se reescribió y se rodó de nuevo?”. Extraída el 28/I/2013 desde http://www.vertele.com/noticias/\%C2\% BFsabia-que-el-primer-capitulo-de-aguila-roja-no-gusto-y-se-reescribio-y-rodo-de-nuevo 